\title{
La terminología embriológica internacional y los epónimos
}

\section{The international embryological terminology and the eponyms}

\author{
Samar Romani M E ${ }^{1}$, Avila Uliarte $\mathrm{RE}^{2}$, Aja Guardiola $\mathrm{S}^{3}$, Fernández Calderón JE ${ }^{1,}$ \\ Fontana Trebino $\mathrm{S}^{1}$, Gómez Rosso $\mathrm{MA}^{1}$ \\ ${ }^{1}$ Departamento de Biología Bucal. Facultad de Odontología. Universidad Nacional de Córdoba. Argentina. \\ ${ }^{2}$ Cátedra de Biología Celular, Histología y Embriología. Facultad de Ciencias Médicas. Universidad Nacional de Córdoba. Argentina. \\ ${ }^{3}$ Facultad de Medicina Veterinaria y Zootecnia. Universidad Nacional Autónoma de México. Ciudad de México. México. \\ (samarcongreso@gmail.com)
}

\begin{abstract}
In medical language we find a large number of eponyms whose use pays tribute to scientists who described pathology, a sign, a technique, an anatomical or microscopic structure, etc. To pay tribute to those who with their research enriched Medicine and Morphological Sciences particularly and to contribute to the knowledge of the historical Embryology terminology we made an illustrated eponyms glossary for the medical / dental community and the students. To elaborate the glossary, the presence and significance of eponyms in General and Special Embryology books (1950-2018), serial publications, databases and virtual encyclopedias were investigated. Anatomical, Histological and Embryological Terminology Symposia recommend perpetuating eponyms and vernacular folk terms with historical interest only. To use a common scientific language and a single denomination that avoids confusion and optimizes communication and learning, priority should be given to the use of normative terminology.
\end{abstract}

KEY WORDS: international morphological terminology, teaching, research, eponyms, ethic.

\section{Resumen}

El lenguaje médico está lleno de epónimos. Su uso rinde homenaje a científicos que describieron una patología, un signo, una técnica, una estructura anatómica o microscópica, etc. En homenaje a quienes con sus investigaciones enriquecieron la Medicina y las Ciencias Morfológicas en particular, y para contribuir al conocimiento de la terminología histórica de la Embriología realizamos un glosario ilustrado de epónimos para la comunidad médico/odontológica y los estudiantes. Para elaborar el glosario investigamos la presencia y significación de epónimos en textos de Embriología General y Especial (años 1950-2018), publicaciones seriadas, bases de datos y enciclopedias virtuales. Los simposios de Terminología Anatómica, Histológica y Embriológica recomiendan perpetuar epónimos y términos folklóricos vernáculos sólo con interés histórico. Debemos priorizar el uso de la terminología normativa cuyo objetivo es usar un lenguaje científico común y una denominación única que evite confusiones y optimice la comunicación y el aprendizaje.

PALABRAS CLAVE: terminología embriológica internacional, docencia, investigación, epónimos, ética 


\section{Introducción}

En las etapas posteriores a los trabajos anatómicos de Vesalio y Galeno se multiplican las investigaciones en las Ciencias Morfológicas. Se descubren estructuras anatómicas que reciben diferentes nombres según los estudios de numerosos autores, creándose un caos terminológico para nombrar una misma estructura. Ejemplo de ello es el ligamento esfenomandibular, perteneciente a la articulación temporomandibular, que se denomina en diferentes publicaciones como ligamento interespinoso, ligamento timpanomandibular o ligamento esfenomaxilar ${ }^{1-2}$.

Como bien mencionan Losardo et $\mathrm{al}^{3}$, hacia fines del siglo XIX había casi 50.000 términos para nombrar sólo 5.000 estructuras anatómicas. Esto originó una verdadera torre de Babel creando confusión y una barrera para el intercambio de conocimientos científicos.

Así llegamos al año 1895, año en el que se reúnen en la ciudad de Basilea (Suiza) los anatomistas de la época. El célebre anatomista, médico, fisiólogo y embriólogo suizo Wilhelm His fue designado para escribir el código anatómico, aprobándose un listado de 4500 términos en latín al que se denominó Basilea Nomina Anatomica ${ }^{4}$. A propuesta del profesor Adolphe Nicolas se funda en el año 1903 la International Federation of Associations of Anatomists (IFAA), que representaba las sociedades anatómicas a nivel mundial. En 1905 Heinrich Wilhelm Gottfried Waldeyer es designado presidente del Congreso Mundial de Anatomía que se desarrolló en Génova. En dicho congreso se creó una comisión permanente para el estudio del léxico anatómico revisándose la nomenclatura en el año 1933, la que se conoció como Revisión Birmingham (Birmingham Revision, BR) ${ }^{5}$. En Jena (1935) se reúnen en el Congreso de la Sociedad Anatómica Alemana 300 anatomistas que modificaron la nomenclatura existente conocida como Jenaiensa Nomina Anatomica (JNA), donde se eliminaron los epónimos ${ }^{4}-$.

Los profesores $\mathrm{T}$ B Johnston y $\mathrm{G}$ A $\mathrm{G}$ Mitchell son designados encargados del Comité de la Nomenclatura Anatómica
Internacional (IANC), creado en el año 1950 durante el Quinto Congreso de Oxford ${ }^{1}$.

En el Sexto Congreso Mundial de Anatomía realizado en París (1955) se acuerda la adopción de una nomenclatura en latín que se basaba en la Basilea Nomina Anatomica de 1895, la Parisiensia Nomina Anatomica $(P N A)$, y la creación de un comité de nomenclatura internacional, el Paris Nomina Anatomica $^{5}$. Allí se acordaron los siguientes puntos:

-Cada estructura anatómica sería designada con un solo nombre.

-El idioma universal es el latín, traducido al idioma vernáculo.

-Los términos tendrán valor descriptivo e informativo.

-No se deben utilizar epónimos.

Ya en el año 1960, durante el desarrollo del Séptimo Congreso Mundial de Anatomía realizado en la ciudad de Nueva York, se constituyen subcomisiones para elaborar las nomenclaturas correspondientes a Histología y Embriología ${ }^{1}$.

Se realizan las últimas modificaciones a la nomenclatura en el año 1965 en Wesbaden, Alemania. Surge así la Nómina Anatómica y en el Noveno Congreso realizado en Leningrado en 1970 se presentan las tres nóminas: Anatomía Macroscópica, Histológica o Microscópica y la Embriológica o del Desarrollo ${ }^{1}$.

En la ciudad de Tokio se realiza el Décimo Congreso durante el año 1975 y se hacen correcciones a las nóminas las que son definitivamente aceptadas en México durante el Undécimo Congreso Mundial de Anatomía ${ }^{6}$.

En Londres se realiza el Duodécimo Congreso Mundial (1985) donde se recomiendan textos de Anatomía, Histología y Embriología los que deben emplear la nóminas ${ }^{1}$.

En Río de Janeiro el Federal Committee on Anatomical Terminology (FCAT, actualmente FICAT) realiza un congreso donde el término nómina es reemplazado por el de terminología ${ }^{3}$, entendiéndose por terminología el conjunto de términos o vocablos propios de determinada profesión, ciencia o materia (RAE) ${ }^{7}$.

IFAA estableció una serie de reglas para denominar estructuras morfológicas ${ }^{3}$ : 
-Deben ser denominados con un término único, descriptivo y explicativo

-El lenguaje empleado debe ser el latín

-La descripción se debe referir a la geometría y forma

-Se deben eliminar los epónimos

En el año 2017 se presenta la segunda edición de Terminologia Embryologica. International Embryological Terminology, FICAT. Esta edición se pondrá en consideración para su aprobación por la Asamblea General en el próximo congreso de IFAA (2019).

En el año 1966 se crea la Asociación Panamericana de Anatomía. En 2009 surgen los Simposios Iberolatinoamericanos de Terminología (SILAT) pertenecientes a la Asociación Panamericana de Anatomía, donde se revisan, discuten, proponen $\mathrm{y}$ unifican criterios en torno a las modificaciones de la terminología morfológica macroscópica, microscópica y embriológica existente 9 .

Por otro lado, en la terminología médico científica se puede descubrir un desmedido listado de palabras conocidas como epónimos. La eponimia es el señalamiento de un detalle anatómico, histológico o embriológico que emplea el nombre de una persona $y$ no proporciona ninguna información relevante, informativa ni descriptiva sobre dicho detalle.

Es bien conocido que entre los siglos XVIII y comienzos del siglo $\mathrm{XX}$ era muy común designar estructuras histológicas $\mathrm{y}$ anatómicas, enfermedades y síndromes con los apellidos de sus descubridores, otorgándoles a los mismos una gran importancia histórica. Sin embargo, en la actualidad la terminología morfológica internacional tiene como uno de sus objetivos principales la desaparición de los epónimos.

No obstante, como un reconocimiento y homenaje a quienes con sus investigaciones enriquecieron a la Medicina y a las Ciencias Morfológicas en especial, y para contribuir al conocimiento de la TERMINOLOGIA HISTORICA de la Embriología, elaboramos un diccionario de epónimos embriológicos que complementa al que presentamos en SILAT XII Costa Rica (año 2015) sobre epónimos en Histología.

\section{Métodos}

Se realizó un estudio descriptivo sobre la presencia y significado de los epónimos en Embriología que se complementó con una pequeña reseña biográfica de los descubridores. Para ello se utilizaron textos de Embriología editados entre los años 1950 y 2018, publicaciones periódicas, bases de datos, enciclopedias virtuales $\mathrm{y}$ otros materiales especializados en el tema. Se procesaron los datos relevados y se realizó un glosario (lista de palabras específicas de una disciplina) al que denominamos HISTORIA DE LA EMBRIOLOGIA: GLOSARIO DE EPONIMOS.

\section{Resultados}

El glosario consta de los epónimos, su significado, su denominación según la terminología embriológica internacional actual y la biografía de quienes dieron nombre a las distintas estructuras.

A modo de ejemplo se ilustra el contenido del trabajo con las Fig. 1 a 4.

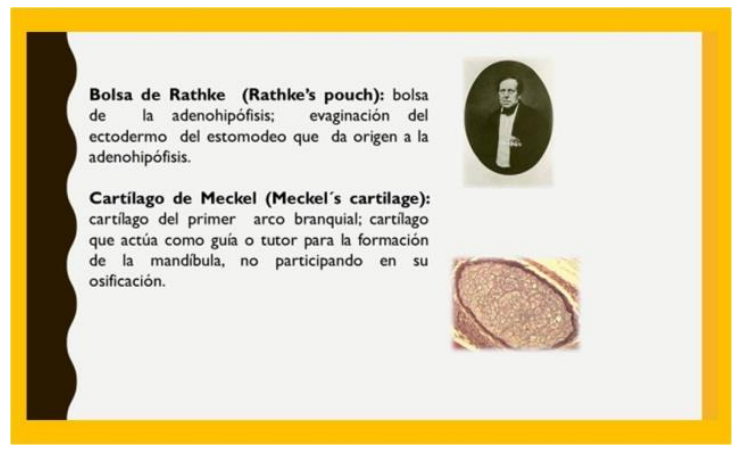

Figura 1

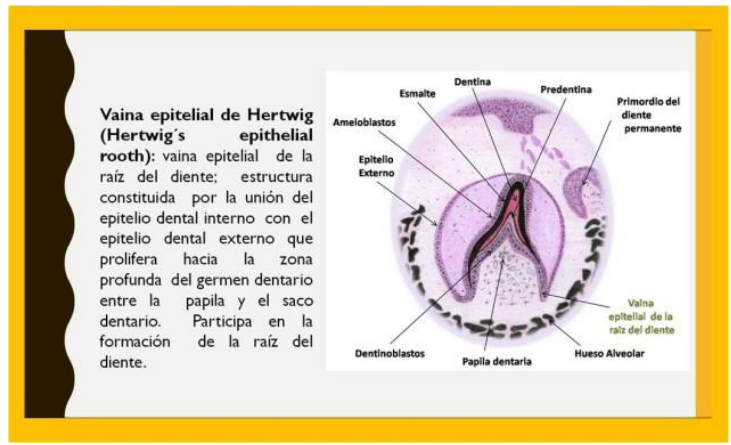

Figura 2 


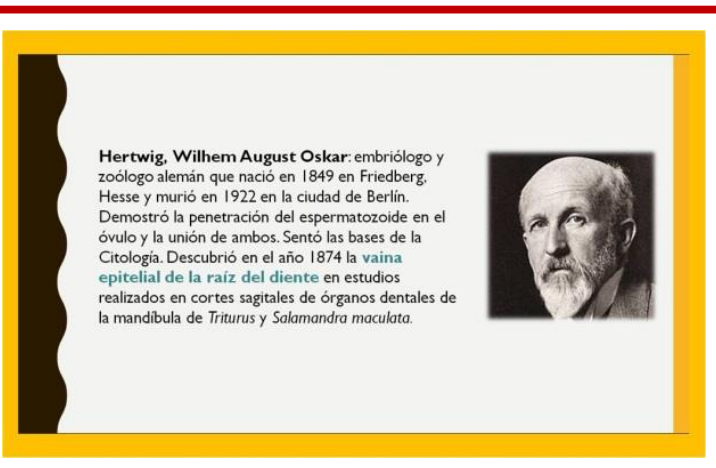

Figura 3

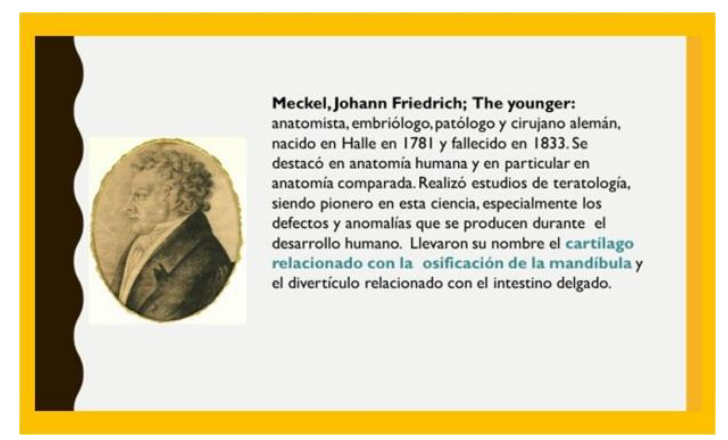

Figura 4

\section{Discusión}

En San José de Costa Rica (abril de 2009) se realizó el I Simposio Ibero-latinoamericano de Terminología Anatómica e Histológica (SILAT), organizado por la Asociación Panamericana de Anatomía (APA). En dicho Simposio se redactó el acta fundacional de los SILAT, firmada por los profesionales de las Ciencias Morfológicas de Latinoamérica y autoridades de APA presentes. A partir de dicha fecha se realizaron distintos simposios en los países de la región avanzando en la traducción de la terminología anatómica, embriológica e histológica en latín al idioma vernáculo'. Como bien describen Cruz Gutiérrez y col el SILAT es "un programa científico y educativo multinacional que sirve de instrumento para analizar y solucionar los problemas de terminología médica morfológica en los países de habla hispana y portuguesa de América"9.

Si por medio de los SILAT se logra igualar la terminología de las estructuras anatómicas, histológicas y embriológicas para manejar un lenguaje científico unificado, el mismo se podrá incorporar a los programas de estudio universitario de grado y posgrado, textos y publicaciones periódicas.
Actualmente los epónimos, sinónimos y la polisemia continúan planteando controversias en la terminología científica. Un sinónimo es un vocablo que tiene una misma o parecida significación que otro. Hay casos en que una enfermedad puede denominarse con 20 o 30 sinónimos diferentes. Por ejemplo síndrome de Costen, síndrome de disfunción de la ATM, disfunción temporomandibular, síndrome de disfunción cráneo-mandibular, desorden temporo-mandibular, síndrome dolordisfunción de la ATM, síndrome disfuncional temporo-mandibular, etc.

Polisemia es la pluralidad de significados de una palabra o de cualquier signo lingüístico. Por ejemplo, enfermedad de Abrami; claudicación intermitente, esclerosis lateral amiotrófica, artropatía diabética, reumatismo articular crónico.

Los epónimos usados en la enseñanza de las ciencias morfológicas se consideran un "homenaje" al "descubridor" de un hallazgo anatómico; lo cual, no siempre ha sido ni verdadero, ni justo ya que de los mismos surgen debates sobre el origen de un descubrimiento.

Un claro ejemplo lo representa el epónimo corpúsculo de Vater-Pacini (corpusculum lamellosum/corpúsculos laminares). El primero que informó sobre estas estructuras fue el anatomista alemán Abraham Vater y luego lo hizo el anatomista italiano Filippo Pacini quien realizó su publicación. Pero realmente fueron descubiertos por el estudiante de Medicina Johannes Gottlieb Lehmann en su tesis doctoral como bien describen Duque Parra y col.

En cuanto a las células de Clara, un tipo celular del epitelio bronquiolar que contribuye a la formación del surfactante pulmonar, fueron descriptas por Max Clara, un anatomista tirolés que en 1937, a partir de estudios realizados en tejidos de prisioneros ejecutados sin conocimiento de sus familiares. En "honor a él" se le denominó: 'célula de Clara', y fue su discípulo Schiller quien promovió el empleo de este particular epónimo en Alemania. Por imitación, en Francia, Policard et al emplearon el epónimo 'cellule de Clara' en 1955; de allí, salió a otros países e idiomas del mundo ${ }^{10-12}$. En la terminología histológica internacional actual, se denomina a esta célula 
exocrinocytus bronchiolaris: Código H3 .05.02.0.00008). Como 'célula de Clara' continúa apareciendo actualmente en algunos libros de Histología como Sobotta Histología (Welsch y Deller, 2014; Histología con correlaciones funcionales y clínicas (DongmeiCui, 2011), etcétera. Consideramos que se debe desterrar su uso no sólo por la recomendación de que la terminología debe ser descriptiva y explicativa sino fundamentalmente por los más elementales principios éticos, porque Clara fue una figura controvertida de la medicina que durante el régimen nazi, realizó sus investigaciones con los cuerpos de los prisioneros sentenciados a ejecución ${ }^{12}$. En nuestro trabajo, reiteramos que dicho epónimo deberá ser eliminado y recomendamos el de: exocrinocito bronquiolar.

En relación a la Morfología, como mencionamos antes, las designaciones ambiguas de las estructuras, basadas en analogías de forma, nombre de maestros, epónimos y sinónimos dificultan la comunicación científica.

Esto, llevó a la aparición de la terminología morfológica internacional -descriptiva y explicativa y sin epónimos- con el objetivo de utilizar un lenguaje científico común, y una única denominación internacional, lo que impide confusiones, precisa, optimiza, homogeniza y homologa la comunicación y el proceso de enseñanza-conocimientoaprendizaje. Se debe considerar que los epónimos no respetan los dos principios fundamentales del lenguaje científico: Precisión y Univocidad.

Es por ello que en la Carrera de Odontología de la Universidad de Córdoba (Argentina) un grupo de docentes de la asignatura Histología y Embriología decidimos trabajar con los estudiantes que recién comienzan la carrera para que conozcan, apliquen y difundan la nueva terminología.

La terminología es útil como una herramienta única de comunicación entre las personas a nivel global.

Destacamos que una terminología científica común de los docentes e investigadores de las Ciencias de la Salud es de fundamental importancia ya que permitirá su integración internacional.
En nuestro medio son muchos los que desconocen la existencia de esta terminología. Pero también están los que la conocen pero son refractarios a su aplicación, en especial en las instituciones educativas.

Utilizar la Terminología Anatómica, Histológica y Embriológica Internacional es una responsabilidad ética y profesional de los docentes e investigadores de la educación superior universitaria. El empleo de las fuentes internacionales de terminología morfológica es la base para una docencia seria, razonada y honesta ${ }^{12,13}$.

Por último, los Simposios de Terminología Internacional (SILAT), así como los autores de esta comunicación recomiendan que los epónimos se deban considerar sólo con interés histórico, sin otorgarles valor académico-docente.

Todos los autores declaran que no existen conflictos potenciales de interés con respecto a la autoría y / o publicación de este artículo.

All authors declare no potential conflicts of interest with respect to the authorship and/or publication of this article.

\section{Referencias}

1. Alvarez Guisbert O, Campohermoso Rodríguez O. Evolución histórica conceptual de la Terminología Anatómica. Rev Cuadernos 2007; 52: 113-7.

2. Fuentes R, Bucchi C, Cantín M. Análisis de los términos utilizados en la literatura científica para referirse a los ligamentos extracapsulares de la articulación témporomandibular. Parte 1: Ligamentum sphenomandibulare. Int J Morphol 2014; 32: 981-6.

3. Losardo RJ, Valverde Barbato de Prates NE, Arteaga-Martínez M, García Peláez MI, Cabral RH. International Morphological Terminology (Anatomy, Histology and Embryology): beyond scientific terms. J Morphol Sci 2017; 34: 130-3.

4. Algieri RD, Pró EA, Forlizzi V, Ferrante MS. Reseña de la evolución histórica de los términos anatómicos. Rev Arg Anat 2011; 2: 106-11.

5. Vandaele S, Gingras Harvey M. Les nomenclatures anatomiques: histoire et traduction. Panace@ 2013; 14: 222-34.

6. Ponte Hernando F. La Nómina Anatómica: historia breve. Cad Aten Primaria 2014; 20: 11620. 
7. Real Academia Española (RAE). At: www.rae.es. Ultimo acceso: Noviembre 14, 2018.

8. Federative International Committee on Anatomical Terminology. Terminologia Histologica. International terms for human Cytology and Histology. Philadelphia. FICATWolters Kluwer/Lippincott Williams \&Wilkins. 2008: 42-8.

9. Cruz Gutiérrez R, Rodríguez Torres A, Prates JC, Losardo RJ, Valverde Barbato de Prates NE. Simposio Ibero-latinoamericano de Terminología Morfológica. Características generales. Int $\mathrm{J}$ Morphol 2010; 643-6.

10. Winkelmann A, Noack T. The Clara cell: a “Third Reich eponym?". Eur Respir J 2010; 36: 722-7.

11. Clara M. Zur Histobiologie des Bronchalepithels [On the histobiology of the bronchial epithelium]. Z mikrosk anat Forsch. 1937; 41:321-47.

12. Woywodt A, Lefrak S, Matteson E. Tainted eponyms in medicine: the "Clara" cell joins the list. Eur Respir J. 2010; 36:706-8.

13. Aja Guardiola S, Olmedo Pérez G, Ríos Más C, Aragón Hernández J, Guajardo Garza ZR, Alemán Castillo JA, Cuellar Salas R, Vela Olivares A, Domínguez Calderón G. Ética de la enseñanza de la terminología morfológica internacional. 10 preguntas al docente del área morfológica. 2011. En www.histologiavirtual.com.ar. Ultimo acceso: 20 de noviembre, 2018.
Correspondencia a/Corresponding to:

Dra. María Elena Samar

${ }^{I}$ Departamento de Biología Bucal. Facultad de Odontología. Universidad Nacional de Córdoba. Argentina Correo electrónico/E-mail: samarcongreso@gmail.com 